\title{
New Magnetic and Luminescent Dy(III) and Dy(III)/Y(III) Based Tetranuclear Silsesquioxane Cages
}

Alena N. Kulakova, ${ }^{[\mathrm{a}],[\mathrm{b}],[\mathrm{c}] \&}$ Karina Nigoghossian, ${ }^{[\mathrm{c}] \&}$ Gautier Félix, ${ }^{[\mathrm{c}]}$ Victor N. Khrustalev, ${ }^{[\mathrm{b}],[\mathrm{d}]}$ Elena S. Shubina, ${ }^{[\mathrm{a}]}$ Jérôme Long, ${ }^{[\mathrm{c}]}$ Yannick Guari, ${ }^{[\mathrm{c}]}$ Luis D. Carlos, ${ }^{[\mathrm{e}]}$ Alexey N. Bilyachenko, ${ }^{*[\mathrm{a}],[\mathrm{b}]}$ and Joulia Larionova*[c] $^{[c]}$

[a] Dr. A.N. Kulakova, Prof. A.N. Bilyachenko, Prof. E.S. Shubina Nesmeyanov Institute of Organoelement Compounds, Russian Academy of Sciences

Vavilova str., 28, Moscow, 119991, Russia

E-mail: bilyachenko@ineos.ac.ru

[b] Dr. A.N. Kulakova, Prof. A.N. Bilyachenko, Prof. V.N. Khrustalev Peoples' Friendship University of Russia, (RUDN University) Miklukho-Maklay Str., 6, 117198, Moscow, Russia

[c] Dr. A.N. Kulakova, Dr. K. Nigoghossian, Dr. G. Félix, Dr. J. Long, Dr. Y. Guari, Prof. J. Larionova ICGM, Univ. Montpellier, CNRS, ENSCM, Montpellier, France,

E-mail: joulia.larionova@umontpellier.fr

[d] Prof. V.N. Khrustalev

Zelinsky Institute of Organic Chemistry, Russian Academy of Sciences

Leninsky Prospect 47, Moscow 119991, Russia

[e] Prof. L. D. Carlos

Phantom-g, Physics Department and CICECO -Aveiro Institute of Materials, University of Aveiro, 3810-193, Aveiro, Portugal.

\& These authors contribute equally to this work

\begin{abstract}
We report here the synthesis, structure, luminescence, and magnetic properties of three new cage-like tetranuclear silsesquioxanes $\left(\mathrm{Et}_{4} \mathrm{~N}\right)_{2}\left[\left(\mathrm{PhSiO}_{1 . .5}\right)_{8}\left(\mathrm{Y}_{0.75} \mathrm{Dy}_{0.25} \mathrm{O}_{1.5}\right)_{4}(\mathrm{O})\left(\mathrm{NO}_{2.5}\right)_{6}(\mathrm{EtOH})_{2}(\mathrm{MeCN})_{2}\right]$ and $(\mathrm{Cat})_{2}$ $\left[\left(\mathrm{PhSiO}_{1.5}\right)_{8}\left(\mathrm{DyO}_{1.5}\right)_{4}(\mathrm{O})\left(\mathrm{NO}_{2.5}\right)_{6}(\mathrm{EtOH})_{2}(\mathrm{MeCN})_{2}\right]\left(\mathrm{Cat}=\mathrm{Et}_{4} \mathrm{~N}\right.$ or $\left.\mathrm{Ph}_{4} \mathrm{P}\right)$. They present a characteristic greenyellow emission. The $\mathrm{Y}^{3+} / \mathrm{Dy}^{3+}$ compound displays in addition a field-induced Single Molecule Magnet (SMM) behavior making it the first reported bifunctional magneto-luminescent silsesquioxane.
\end{abstract}


Lanthanide ions-based coordination compounds have attracted a great deal of attention for several decades due to their tremendous optical and magnetic properties. On one hand, they exhibit narrow emission bands in the visible and Infra-Red spectral regions due to the $4 f-4 f$ transitions suitable for different applications in displays, sensors, imagery, luminescent immunoassays and others. ${ }^{1}$ On the other hand, the recent discovery of lanthanide-based Single Molecule Magnets (SMMs) exhibiting a slow relaxation of the magnetization associated with magnetic bistability at the molecular scale at temperatures surpassing the temperature of liquid nitrogen renders the lanthanide complexes extremely interesting as memory units for upcoming applications in spintronic. ${ }^{2}$ For these reasons, the coordination chemistry of lanthanide ions employed in association with numerous ligands in the aim to design mono and polynuclear compounds has been the subject of a huge development during recent decades. ${ }^{3}$ In this line of thought, a particular attention has been done to design of multifunctional magneto-luminescent SMMs because they not only can exhibit a slow relaxation of the magnetization and a characteristic $\operatorname{Ln}^{3+}$ emission, ${ }^{4}$ but, in some cases involving mononuclear $\mathrm{Dy}^{3+}$ based compounds, the correlation of the energy gap between the ground and excited states determined from the luminescence and the energy barrier obtained by magnetic measurements was established. ${ }^{5}$

Surprisingly, the introduction of lanthanides into cage-like metallasilsesquioxanes (CLMSs) has received much less attention. In this connection, only two families of lanthanide-based CLMSs have been reported up to now. ${ }^{6}$

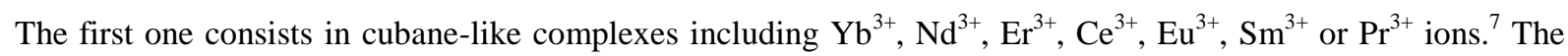
second one is sandwich-like silsesquioxane cages containing a tetranuclear oxo-lanthanide core (including $\mathrm{La}^{3+}$, $\mathrm{Nd}^{3+}, \mathrm{Gd}^{3+}$ and $\left.\mathrm{Dy}^{3+}\right){ }^{8}$ It should be pointed out that these CLMSs have mainly been designed and investigated regarding their potential catalytic activity, ${ }^{9}$ whereas magnetic and optical properties have been considered only scarcely. In this connection, only one study reported the luminescence of a mononuclear $\mathrm{Eu}^{3+}$-based CLMS, but its crystal structure has not been elucidated. ${ }^{10}$ Very recently, we reported on the first example of $\mathrm{Tb}^{3+} \mathrm{and}^{\mathrm{Eu}^{3+}-}$ based cage silsesquioxanes with a full characterization of their X-ray structures and bi-functional (magnetic/luminescent) properties. ${ }^{11}$ Yet, the lack of magnetic anisotropy precludes the observation of a slow relaxation of the magnetization.

In the present communication we report on the synthesis, crystal structure and investigation of optical and magnetic properties of three new tetranuclear $\mathrm{Dy}^{3+}$ and mixed $\mathrm{Y}^{3+} / \mathrm{Dy}^{3+}$ based CLMSs. All of them present Dy ${ }^{3+}$ characteristic emission, while the mixed $\mathrm{Y}^{3+} / \mathrm{Dy}^{3+}$ compound exhibits in addition a field induced slow relaxation of the magnetization making it the first multifunctional SMM CLMS. Moreover, we performed the correlation between the photo-emission and the magnetic properties.

The synthesis of anionic lanthanide-based CLMSs has been performed by adapting the previously described ${ }^{11}$ procedure consisting in two-step reaction involving firstly the in-situ formation of phenylsiloxanolate $[\mathrm{PhSi}(\mathrm{O}) \mathrm{ONa}]_{\mathrm{x}}$ species with their following self-assembling reaction with the $\mathrm{Dy}^{3+}$ or the $\mathrm{Dy}^{3+} / \mathrm{Y}^{3+}$ salts $(1 / 3$ stoichiometry) and $\mathrm{Et}_{4} \mathrm{NCl}$ or $\mathrm{Ph}_{4} \mathrm{PCl}$ (Figure S1, see Supporting Information for details). The crystallization from an acetonitrile/ethanol mixture affords the formation of single crystals suitable for X-Ray diffraction with chemical formula $\left(\mathrm{Et}_{4} \mathrm{~N}\right)_{2}\left[\left(\mathrm{PhSiO}_{1.5}\right)_{8}\left(\mathrm{Y}_{0.75} \mathrm{Dy}_{0.25} \mathrm{O}_{1.5}\right)_{4}(\mathrm{O})\left(\mathrm{NO}_{2.5}\right)_{6}(\mathrm{EtOH})_{2}(\mathrm{MeCN})_{2}\right]$ $(\mathrm{Cat})_{2}\left[\left(\mathrm{PhSiO}_{1.5}\right)_{8}\left(\mathrm{DyO}_{1,5}\right)_{4}(\mathrm{O})\left(\mathrm{NO}_{2.5}\right)_{6}(\mathrm{EtOH})_{2}(\mathrm{MeCN})_{2}\right]\left(\right.$ where Cat=Et $\left.{ }_{4} \mathrm{~N}(\mathbf{2}), \mathrm{Cat}=\mathrm{Ph}_{4} \mathrm{P}(\mathbf{3})\right)$. X-Ray diffraction analysis indicates that the compounds $\mathbf{1}-\mathbf{3}$ crystallize in the $P-1$ space group and present very similar crystal 


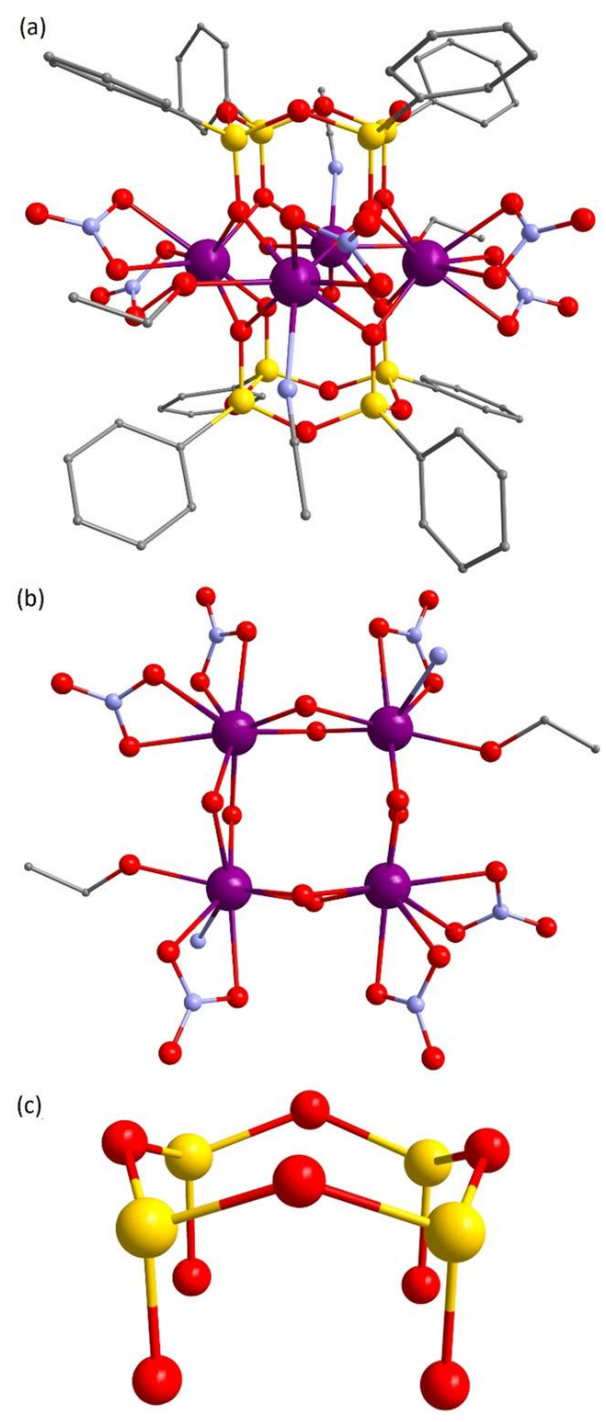

Figure 1: (a) Molecular structure of 1. Hydrogen atoms and crystallized ethanol and acetonitrile molecules have been omitted for clarity. A statistical distribution of Dy and Y was considered. (b) Representation of the core fragment of 1 showing the coordination geometry of Dy/Y sites. (c) Representation of the cyclic tetraphenylcyclotetrasiloxanolate fragment. Color code: purple, Dy/Y; yellow, Si; red, O; blue, N, grey, C.

structures (CCDC 2062487 (1), CCDC 2002354 (2) and CCDC 2002355 (3)). The relevant parameters for them are summarized in Table S1, Supporting Information.

The molecular structure of $\mathbf{1}$ contains $\mathrm{Et}_{4} \mathrm{~N}^{+}$cation and an anionic CLMS moiety. The latter may be viewed as a prism-like polyhedron, which looks like a new year paper lantern. It consists of a $\left(\mathrm{Y}_{0.75} \mathrm{Dy}_{0.25} \mathrm{O}_{1.5}\right)_{4}$ core situated in the middle inserted between two cyclic tetraphenylcyclotetrasiloxanolate ligands (Figure 1a). It should be noted that ligands of such particular type is a rare feature for CLMSs, reported earlier for titanium- ${ }^{12}$ iron-,${ }^{13}$ cobalt-,${ }^{14}$ zinc-based ${ }^{15}$ silsesquioxanes. The core of $\mathbf{1}$ has a shape of a distorted square in which the $\mathrm{Ln}^{3+}$ ions are linked through bridging oxygen atoms (Figure 1b). A statistical distribution of Y/Dy was considered. There are two different $\mathrm{Dy} / \mathrm{Y}$ sites, being both eight coordinated with a distorted square antiprism geometry. The first one is coordinated by four bridging oxygens and four oxygens from two nitrates, while the second is surrounded by four bridging oxygens, one acetonitrile and one ethanol molecules. The $\mathrm{Ln}-\mathrm{O}$ distances involving bridging 
oxygens are in the range 2.2451(1)-2.3340(1) $\AA$, while those involving terminal nitrates and ethanol molecule are in the range 2.3900(2)-2.5784(2) $\AA$. The Ln-O angles in the square are in the range 70.731(3)-82.060(3) ${ }^{\circ}$. The Dy/Y-N distances are equal to 2.5358(2) and 2.4933(1) $\AA$. The crystal packing shown in the $b c$ plane (Figure S2, Supporting Information) indicates that the anionic molecular moieties are almost aligned along the $b$ axis and alternated with $\mathrm{Et}_{4} \mathrm{~N}^{+}$cations. The shortest intermolecular Dy...Dy distance is equal to 7.9580(2) $\AA$. The molecular structures of $\mathbf{2}$ and $\mathbf{3}$ are quite similar to $\mathbf{1}$ (Figure S3-S6, Supporting Information). The relevant distances and angles are summarized in Table S2, Supporting Information.

The magnetic properties have been performed by using a SQUID MPMS-XL magnetometer working in 1.8-300 $\mathrm{K}$ temperature range up to $7 \mathrm{~T}$ in the direct current (dc) and alternating current (ac) modes. The temperature dependence of the magnetic susceptibility performed for $\mathbf{1 - 3}$ under an applied magnetic field of 1000 Oe is shown in Figure 2a. The obtained room temperature $\chi T$ values of 14.2, 56.9 and $53.7 \mathrm{~cm}^{3} \mathrm{~K} \mathrm{~mol}^{-1}$ for $\mathbf{1}, \mathbf{2}$ and $\mathbf{3}$, respectively, correspond well to the values expected for one $\left(14.2 \mathrm{~cm}^{3} \mathrm{~K} \mathrm{~mol}^{-1}\right)$ and four $\left(56.7 \mathrm{~cm}^{3} \mathrm{~K} \mathrm{~mol}^{-1}\right) \mathrm{Dy}^{3+}$ ions in the free-ion approximation $(J=15 / 2, g=4 / 3) .{ }^{16}$ Upon cooling, the compounds exhibit the classical decrease of $\chi T$ caused by the thermal depopulation of the Kramers doublets and by the possible presence of
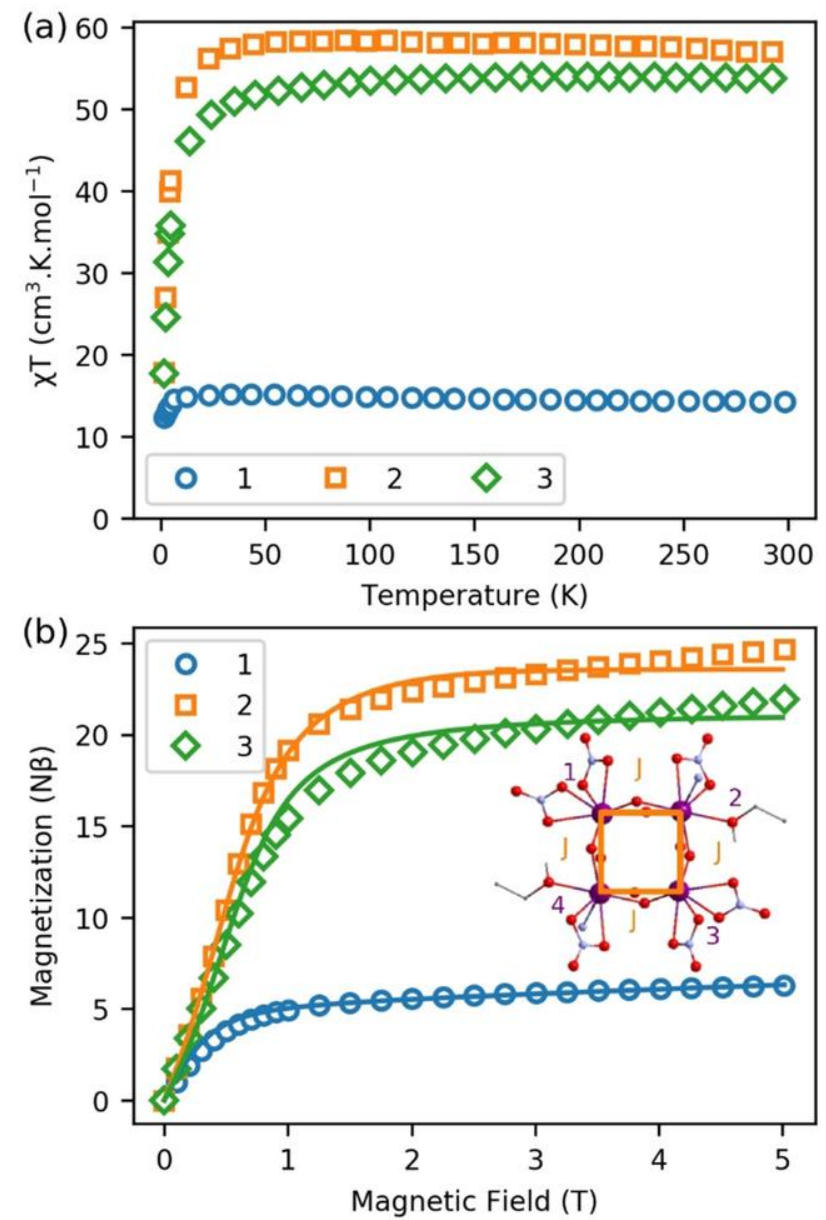

Figure 2: (a) Temperature dependence of $\chi T$ under a 1000 Oe dc magnetic field for 1-3. (b) Field dependence of the magnetization at $1.8 \mathrm{~K}$ for $\mathbf{1 - 3}$. The solid lines represent theoretical fits with the PHI software. Inset: a schematic representation of the considered magnetic exchange interactions between Dy ${ }^{3+}$ ions in $\mathbf{2}$ and $\mathbf{3}$. 
antiferromagnetic interactions between the $\mathrm{Dy}^{3+}$ centers for $\mathbf{2}$ and $\mathbf{3}$ (Figure 2a).

The field dependences of the magnetization performed at $1.8 \mathrm{~K}$ for $\mathbf{1}-\mathbf{3}$ show a S-shape curve for 2 and $\mathbf{3}$ suggesting the presence of a spin flip of magnetic moment under an applied magnetic field related to antiferromagnetic interaction, ${ }^{17}$ while a linear increase of the magnetization at low fields is observed for $\mathbf{1}$. The three curves never reach saturation and the magnetization values of 6.3, 24.6 and $21.9 \mathrm{~N} \beta$ under 5 Tesla field for $\mathbf{1}, \mathbf{2}$ and 3, respectively, indicate the presence of a significant magnetic anisotropy (see Figure $2 b$ ). In the case of 1 containing a statistically distributed dysprosium ion in the tetranuclear core, $\chi T$ vs $T$ and $M$ vs $H$ curves were fitted with the PHI software by using the Hamiltonian taking into account the Zeeman and the Stevens operator order terms and with $m J=15 / 2$ and $g=4 / 3$ for $\mathrm{Dy}^{3+}$ in $1 .{ }^{18}$ For CLMSs 2 and $\mathbf{3}$ containing four Dy ${ }^{3+}$ ions, their contribution was approximated as 4 pseudospins $(\tilde{S}=1 / 2)$, associated with a diagonal $g$-tensor with the diagonal components $g_{x}, g_{y}$ and $g_{z}$, allowing to take into account the magnetic anisotropy. Magnetic interactions $(J)$ between the four pseudospins were also included in the model (see insert of Figure 2b). The obtained parameters (Tables S3, Supporting Information) confirm the expected important magnetic anisotropy for Dy ${ }^{3+}$ in these compounds and the presence of antiferromagnetic interactions for $\mathbf{2}$ and $\mathbf{3}$, which may explain the observed S-shape $M$ vs $H$ curves.

The dynamic measurements in the ac mode have been performed for three CLMSs, but only sample $\mathbf{1}$ demonstrated a slow relaxation of the magnetization. This fact may be explained by the presence of magnetic interactions between $\mathrm{Dy}^{3+}$, which negatively affect the relaxation dynamics. ${ }^{19}$ For CLMS 1, the in-phase, $\chi$, and the out-of-phase, $\chi$ ', components of the ac susceptibility did not present an important signal under a zero-dc field, which may be ascribed to the presence of the fast Quantum Tunneling of the Magnetization (QTM). In order to avoid its influence, the frequency dependence of the ac susceptibility was measured under different applied dc fields, which showed a strong signal for both components (Figure S7, Supporting Information). The optimum magnetic field corresponding to the higher relaxation time was determined as 1800 Oe (Inset Figure 3b). The frequency dependence of the ac susceptibility under this field reveals the presence of a series of broad peaks, for which the maxima shift toward higher frequencies as the temperature increases, suggesting the occurrence of a field-induced slow relaxation of the magnetization (Figure 3a, Figure S8, Supporting Information). The temperature and field dependences of the relaxation time were not fitted independently but simultaneously. The following equation was used for the fitting process: ${ }^{20}$

$$
\tau^{-1}=A H^{4} T+\frac{B}{H^{2}}+C T^{m}+\tau_{0}^{-1} \exp \left(-\frac{\Delta}{k_{B} T}\right)
$$



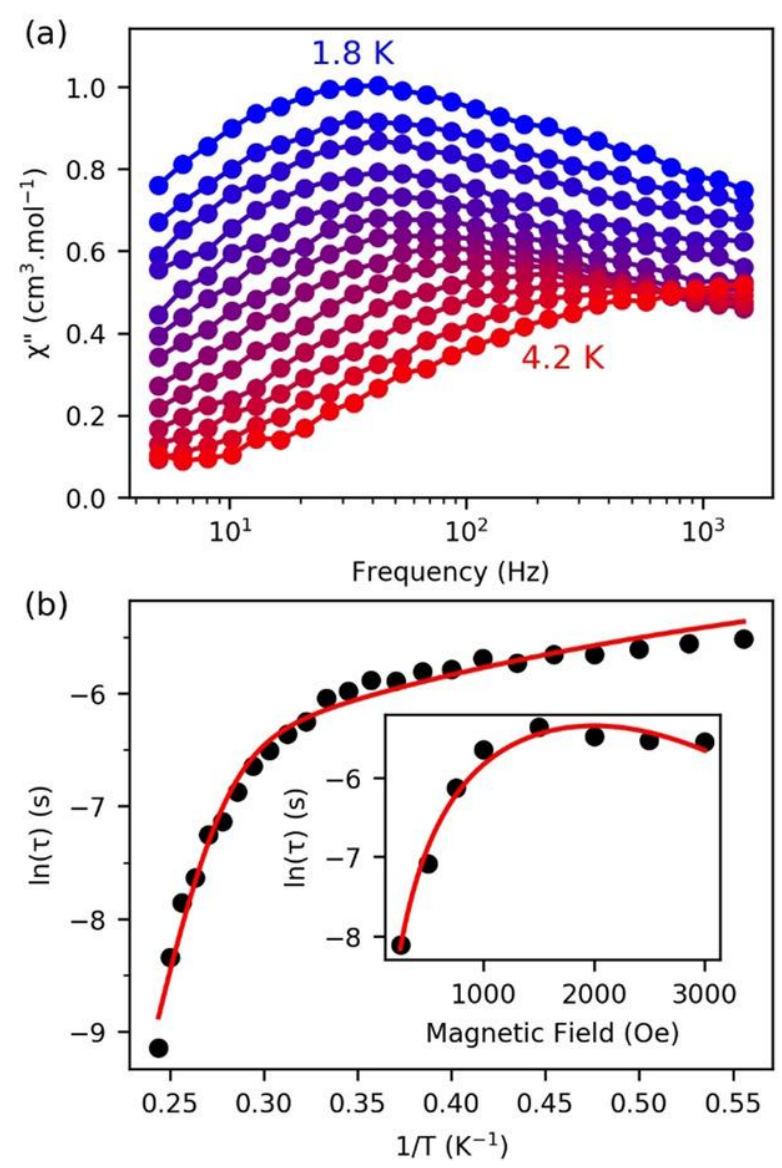

Figure 3: (a) Out-of-phase, $\chi$ ', component of the ac magnetic susceptibility as a function of frequency at different temperature measured under an optimal, $1800 \mathrm{Oe}$, dc field for 1. (b) Temperature dependence of the relaxation time for 1 under 1800 Oe. Inset: Field dependence of the relaxation time for $\mathbf{1}$ at $1.8 \mathrm{~K}$. The red solid lines represent the fits done by using the equation (1). The non-linear least square fitting method was applied simultaneously for both experimental curves.

where the first, second, third and fourth terms represent the relaxation time for the direct, QTM, Raman and Orbach processes, respectively (Figure $3 b$ ). The QTM process is usually known as $B_{1} /\left(1+B_{2} H^{2}\right)$. In our case, to avoid the over-parameterization we can make the approximation $B_{2} H^{2} \gg 1$, which allows to rewrite the second term of the equation as $B / H^{2}$. The obtained value of the energy barrier, $\Delta$, is equal to $49 \pm 4 \mathrm{~cm}^{-1}$ with $\tau_{0}=5.5 \times 10^{-12.0 \pm 0.6} \mathrm{~s}$. The power value $m$ in the Raman term takes the value of $1.7 \pm 0.2$, associated with a coefficient $C$ of $52 \pm 10 \mathrm{~s}^{-1} \mathrm{~K}^{-\mathrm{m}}$. The parameters $B$ and $A$ related to QTM and the direct process, respectively, take the values of $2.0 \times 10^{8} \mathrm{Oe}^{2} \cdot \mathrm{s}^{-1}$ and $7.7 \times 10^{-13} \mathrm{~s}^{-1} \cdot \mathrm{K}^{-1} \cdot \mathrm{Oe}^{-4}$. The obtained parameters suggest an important contribution of Raman process in the magnetic relaxation. Several combinations of relaxation time fit were tested, and only the one including QTM, Raman and Orbach processes was relevant.

The emission spectra 1-3 investigated in the solid state at $298 \mathrm{~K}$ (Figure S9b, Figure S10b, Supporting Information) revealed a typical $\mathrm{Dy}^{3+}$ green-yellow emission under the excitation in the UV region. The excitation spectrum of 1 in the range $250-500 \mathrm{~nm}$ recorded at $77 \mathrm{~K}$ (Figure $4 \mathrm{a}$ ) monitoring the emission at $572 \mathrm{~nm}$ $\left({ }^{4} \mathrm{~F}_{9 / 2} \rightarrow{ }^{6} \mathrm{H}_{13 / 2}\right.$ transition) shows the characteristic $\mathrm{Dy}^{3+} f-f$ transitions with a higher intensity at $350 \mathrm{~nm}$ 
(a)

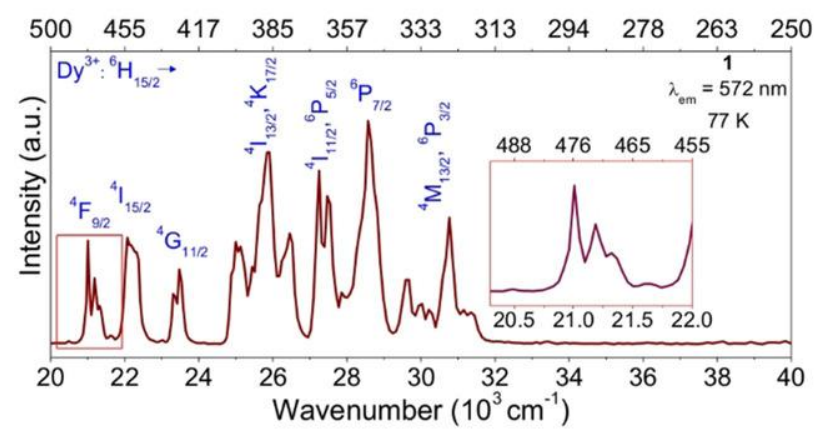

(b)

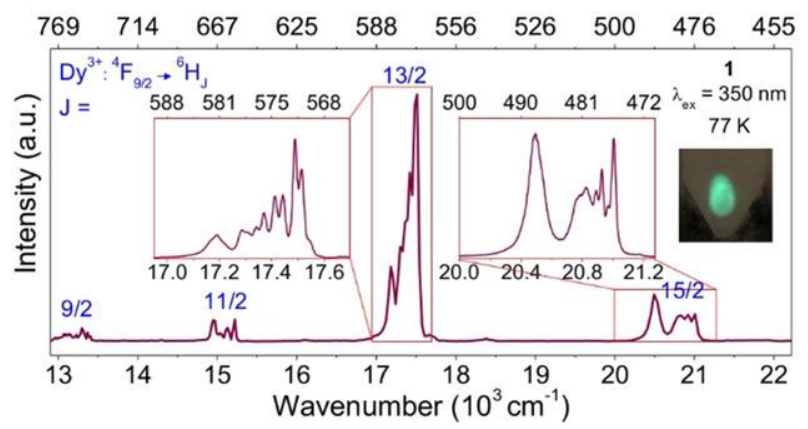

Figure 4: (a) Solid-state excitation spectrum of 1 recorded at $77 \mathrm{~K}$ and monitored at $572 \mathrm{~nm}$. Inset: highresolution spectra in the region of ${ }^{6} \mathrm{H}_{15 / 2} \rightarrow \stackrel{4}{\mathrm{~F}_{9 / 2}}$. (b) Solid-state emission spectrum of $\mathbf{1}$ recorded at $77 \mathrm{~K}$ under excitation at $350 \mathrm{~nm}$. Insets: high-resolution spectra in the region of ${ }_{\mathrm{F}}^{\mathrm{F}}{ }_{9 / 2} \rightarrow \stackrel{6}{\mathrm{H}_{13 / 2}}$ and ${ }_{\mathrm{F}}^{\mathrm{F}}{ }_{9 / 2} \rightarrow{ }^{6} \mathrm{H}_{15 / 2}$ transitions. Inset: photograph of $\mathbf{1}$ under $350 \mathrm{~nm}$-irradiation.

corresponding to ${ }^{6} \mathrm{H}_{15 / 2} \rightarrow{ }^{6} \mathrm{P}_{7 / 2}$. The magnified excitation spectrum (inset of Figure $4 \mathrm{a}$ ) clearly shows four components of the ${ }^{6} \mathrm{H}_{15 / 2} \rightarrow{ }^{4} \mathrm{~F}_{9 / 2}$ transition at 21,$008 ; 21,186 ; 21,322$; and $21,645 \mathrm{~cm}^{-1}$. The excitation spectrum for 1 measured at $298 \mathrm{~K}$ are less resolved, but present similar profiles with three main bands at around 326, 351 and $366 \mathrm{~nm}$ corresponding to the $\mathrm{Dy}^{3+}$ transitions (Figure S9a, Figure S10a, Supporting Information). Such observation indicates that the ligands do not provide an efficient sensitization of $\mathrm{Dy}^{3+}$ emission in these CLMSs.

The solid-state emission spectra for 1 performed at $77 \mathrm{~K}$ was measured between 450 and $780 \mathrm{~nm}$ under excitation at $350 \mathrm{~nm}$ according to the maximum intensity recorded in the excitation spectrum (Figure $4 \mathrm{~b}$ ). The higher resolution of the spectrum recorded at low temperature unravels a series of the characteristic $\mathrm{Dy}^{3+} 4 \mathrm{f}$ transitions ${ }^{4} \mathrm{~F}_{9 / 2} \rightarrow{ }^{6} \mathrm{H}_{9 / 2}$ (between 740 and $766 \mathrm{~nm}$ ), ${ }^{4} \mathrm{~F}_{9 / 2} \rightarrow{ }^{6} \mathrm{H}_{11 / 2}$ (between 660 and $675 \mathrm{~nm}$ ), ${ }^{4} \mathrm{~F}_{9 / 2} \rightarrow{ }^{6} \mathrm{H}_{13 / 2}$ (between 568 and $588 \mathrm{~nm}$ ) and ${ }^{4} \mathrm{~F}_{9 / 2} \rightarrow{ }^{6} \mathrm{H}_{15 / 2}$ (between 470 and $490 \mathrm{~nm}$ ), which correspond to emissions in the red, yellow-green, and blue spectral regions, respectively. The intensity of the hypersensitive ${ }^{4} \mathrm{~F}_{9 / 2} \rightarrow{ }^{6} \mathrm{H}_{13 / 2}$ transition depends on the local site symmetry, whereas the ${ }^{4} \mathrm{~F}_{9 / 2} \rightarrow{ }^{6} \mathrm{H}_{15 / 2}$ intensity usually is not significantly impacted by the Dy ${ }^{3+}$ site geometry. ${ }^{22}$ The emission spectra of $\mathbf{1}$ in the regions of ${ }^{4} \mathrm{~F}_{9 / 2} \rightarrow{ }^{6} \mathrm{H}_{13 / 2}$ and ${ }^{4} \mathrm{~F}_{9 / 2} \rightarrow{ }^{6} \mathrm{H}_{15 / 2}$ transitions was measured with high-resolution at $77 \mathrm{~K}$ (insets of Figure $4 \mathrm{~b}$ ). These bands show a complex profile expected in the case of several $\mathrm{Dy}^{3+}$ sites with slightly different coordination environment, which complicates the analysis. For this reason, to identify the equivalent Kramers doublets, we modelled by multi-Gaussian function only the high-energy window of the high-resolution spectrum for ${ }^{4} \mathrm{~F}_{9 / 2} \rightarrow{ }^{6} \mathrm{H}_{15 / 2}$ transition (Figure 5a). ${ }^{23}$ 
The energy components arising from the first and second ${ }^{4} \mathrm{~F}_{9 / 2}$ Kramers doublets to the ${ }^{6} \mathrm{H}_{15 / 2}$ multiplets are sketched in the energy level diagram (Figure 5b). The presence of two Dy sites generates two groups of bands represented as $\mathrm{A}$ and $\mathrm{B}$ transitions. The $\mathrm{A}_{1}{ }^{*}$ and $\mathrm{B}_{1}{ }^{*}$ hot bands correspond to transitions from the upper emissive ${ }^{4} \mathrm{~F}_{9 / 2}$ state to the ground doublet of the ${ }^{6} \mathrm{H}_{15 / 2}$ state. The degeneracy of the multiplet ${ }^{4} \mathrm{~F}_{9 / 2}$ involves four Kramers doublets with energy values of $21,035,21,089 ; 21,131$, and $21,173 \mathrm{~cm}^{-1}$, which are similar to those observed in the excitation spectrum (inset of Figure 4a). The energy gaps between highest and lowest Stark components of ${ }^{4} \mathrm{~F}_{9 / 2}$ level determined as the difference between $\mathrm{A}_{1}{ }^{*}$ and $\mathrm{A}_{1}$ and $\mathrm{B}_{1}{ }^{*}$ and $\mathrm{B}_{1}$ transitions are equal to $84 \pm 12$ and $96 \pm 16 \mathrm{~cm}^{-1}$, respectively. These values are coherent with the previously reported data. ${ }^{5 \mathrm{c}, 5 \mathrm{f}}$ It could be observed that the energy gaps to bridge the first excited Kramers doublets of the ${ }^{6} \mathrm{H}_{15 / 2}$ state to the ground doublet were $U_{A}=84 \pm 9$ and $U_{B}=70 \pm 10 \mathrm{~cm}^{-1}$. The difference between these values and the energy barrier one of $49 \pm 4 \mathrm{~cm}^{-1}$ found by dynamic magnetic measurements can come from two points: $(i)$ the magnetic measurements are made under an external magnetic field and the luminescent measurements have been done without any field, (ii) no extended linear region may be observed on the $\ln (\tau) v s . T^{-1}$ plot (Figure $3 b$ ), which indicates that there is no pure

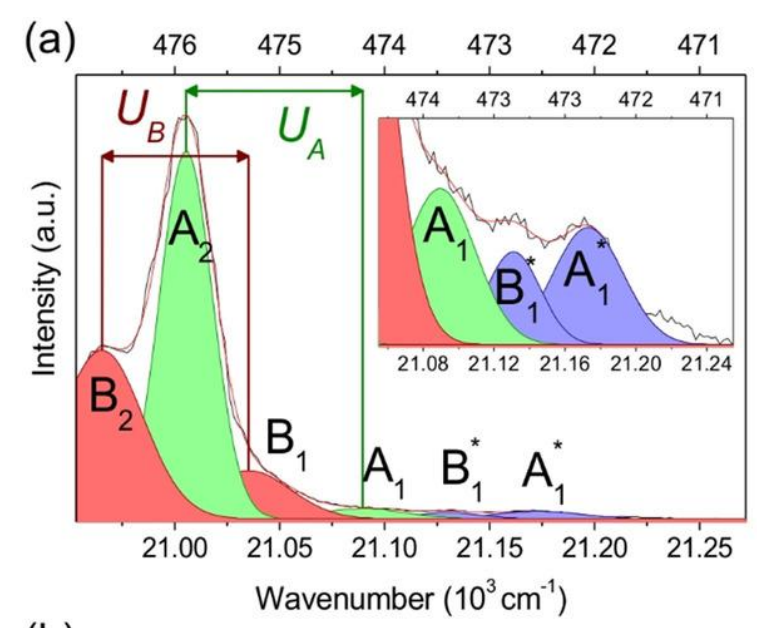

(b)

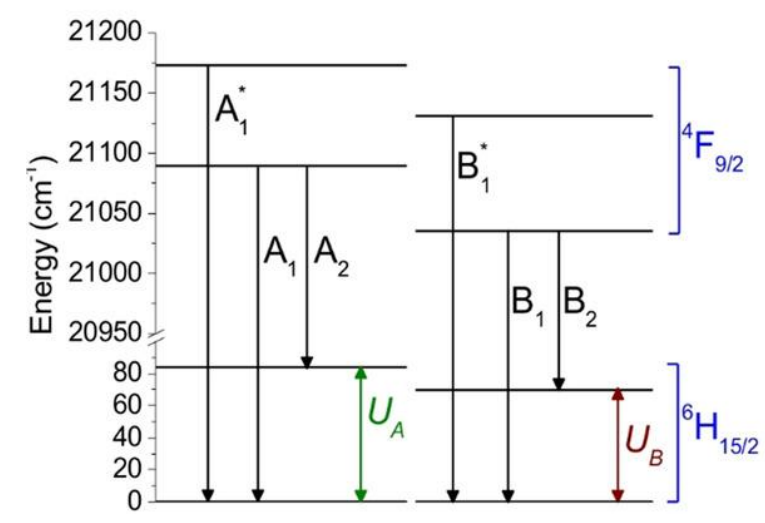

Figure 5: (a) High-resolution emission spectrum of 1 performed at $77 \mathrm{~K}$ under excitation at 350 in the range 20953-21272 $\mathrm{cm}^{-1}$ with multi- Gaussian functions fit (red line) and the components. The inset shows $\mathrm{A}_{1}^{*}$ and $\mathrm{B}_{1} *$ components, which correspond to the hot bands originated from the first ${ }^{4} \mathrm{~F}_{9 / 2}$ Kramers doublets to the ground ground ${ }^{6} \mathrm{H}_{15 / 2}$ multiplet. (b) Simplified energy level diagram of Dy ${ }^{3+}$ with transitions arising from ${ }^{4} \mathrm{~F}_{9 / 2}$ Kramers doublets to the ${ }^{6} \mathrm{H}_{15 / 2}$ multiplet. 
Orbach regime and that the measured effective barrier is underestimated with respect to the crystal-field splitting obtained spectroscopically owing to an overlap with the Raman and QTM processes. ${ }^{5 b, 20 a}$

The emission spectra of $\mathbf{1}, \mathbf{2}$ and $\mathbf{3}$ performed at room temperature present similar profile (Figure S9b, Figure. S10b, Supporting Information), but they are less resolved, and they cannot be improved at low temperature. This fact could be explained by the possible energy transfer between four dysprosium ions located in the core of 2 and 3, which enhances the efficiency of the nonradiative processes. ${ }^{24}$

The emission decay curves measured in the solid state at $77 \mathrm{~K}$ to determine the ${ }^{4} \mathrm{~F}_{9 / 2} \rightarrow{ }^{6} \mathrm{H}_{13 / 2}$ lifetime (Figures S11-S13, Supporting Information) gave typical values for dysprosium-based complexes values of 0.112 \pm 0.002 , $0.167 \pm 0.005$ and $0.160 \pm 0.001 \mathrm{~ms}$, respectively for $\mathbf{1}, \mathbf{2}$ and $\mathbf{3}^{5 \mathrm{c}, 5 \mathrm{f}}$

In summary, three new tetranuclear $\mathrm{Dy}^{3+}$ and $\mathrm{Dy}^{3+} / \mathrm{Y}^{3+}$ based silsesquioxane cages with an unusual prism-like topology have been synthesized and characterized. The $\mathrm{Dy}^{3+} / \mathrm{Y}^{3+}$ compound presents the dysprosium characteristic green-yellow emission and a field induced slow relaxation of the magnetization making it the first multifunctional magneto-luminescent SMM CLMS. The CLMSs containing four $\mathrm{Dy}^{3+}$ ions in the core did not present the slow relaxation of the magnetization due to the presence of magnetic interactions, which negatively influence the magnetic relaxation. Their luminescence is also impacted by the energy transfer between $\mathrm{Dy}^{3+}$, which favors nonradiative processes. This work opens great perspectives for the design of new family of multifunctional CLMSs.

\section{Acknowledgements}

This work was supported by the RFBR (project 19-53-15008). J. La., K. N., G. F., Y. G. and J. Lo. thank the University of Montpellier and CNRS for financial support (project PRC2287 Premium 2019-2021), as well as for the project MAGCELL, which was co-financed by the European Union (European Regional Development Fund) as part of the support of interdisciplinary or innovative research projects in S3 fields of the Occitanie region. The work was also developed within the scope of the project CICECO-Aveiro Institute of Materials, UIDB/50011/2020 \& UIDP/50011/2020, financed by Portuguese funds through the FCT/MEC and, when appropriate, co-financed by FEDER under the PT2020 Partnership Agreement. Authors are grateful to Platform of Analysis and Characterization (PAC) of ICGM for magnetic and X-ray diffraction measurements. J. La. and A. N. K. are grateful to the Vernadski program (Embassy of France in Russian Federation). Elemental analyses were performed with the financial support from the Ministry of Science and Higher Education of the Russian Federation and using the equipment of the Center for Molecular Composition Studies of INEOS RAS. This paper was supported in part by the RUDN University Strategic Academic Leadership Program (A. N. K., A. N. B. and V. N. K.).

\section{Conflict of interest}

The authors declare no conflict of interest.

\section{References}


[1] a) J.-C. G. Bünzli, C. Piguet, Chem. Soc. Rev. 2005, 34, 1048-1077; b)J.-C. G. Bunzli, Coord. Chem. Rev. 2015, 293-294, 19-47; c)J. Andres, A.-S. Chauvin, Molecules 2020, 25, 4022-4040; d) Y. Hasegawa, Y. Kitagawa, J. Mater. Chem. 2019, 7, 7494-7511; e) G. F. de Sá, O. L. Malta, C. de Mello Donegá, A. M. Simas, R. L. Longo, P. A. Santa-Cruz, E. F. da Silva Jr., Coord. Chem. Rev. 2000, 196, 165-195; f) L. Armelao, S. Quici, F. Barigelletti, G. Accorsic, G. Bottaro, M. Cavazzini, E. Tondello, Coord. Chem. Rev. 2010, 254, 487505; g) M. L. Aulsebrook, B. Graham, M. R. Grace, K. L. Tucka, Coord. Chem. Rev. 2018, 375, 191-220; h) Y. Hasegawa, Y. Wada, S. Yanagida, J. Photochem. Photobiol. C 2004, 5, 183-202.

[2] a) R. A. Layfield, M. Murugesu, Lanthanides and actinides in molecular magnetism, Wiley-VCH, Weinheim 2015; b) D. N. Woodruff, R. E. P. Winpenny, R. A. Layfield, Chem. Rev. 2013, 113, 5110-5148; c) L. Bogani, W. Wernsdorfer, Nat. Mater. 2008, 7, 179-186; d) F. Troiani, M. Affronte, Chem. Soc. Rev. 2011, 40, 31193129.

[3] a) S. A. Cotton, Chemistry of Precious Metals, Springer, Netherlands, 1997; b) J.-C. G. Bünzli, J. Coord. Chem. 2014, 67, 3706-3733; c) N. C. Martinez-Gomez, H. N. Vu, E. Skovran, Inorg. Chem. 2016, 55, 1008310089; d) J.-C. G. Bünzli, Acc. Chem. Res. 2006, 39, 53-61; e) R. Janicki, A. Mondry, P. Starynowicz, Coord. Chem. Rev. 2017, 340, 98-133; f) A. W. G. Platt, Coord. Chem. Rev. 2017, 340, 62-78; g) G. Calvez, F. Le Natur, C. Daiguebonne, K. Bernot, Y. Suffren, O. Guillou, Coord. Chem. Rev. 2017, 340, 134-153; h) S. A. Cottona, P. R. Raithby, Coord. Chem. Rev. 2017, 340, 220-231; i) J. A. Kitchen, Coord. Chem. Rev. 2017, 340, 232-246; j) I. V. Lapshin, A. V. Cherkasov, A. F. Asachenko, A. A. Trifonov, Chem. Commun. 2020, 56, 12913-12916; k) Q. Zhang, J. Wang, A. M. Kirillov, W. Dou, C. Xu, C. Xu, L. Yang, R. Fang, W. Liu, ACS Appl. Mater. Interfaces 2018, 10, 23976-23986; 1) A. Karmakar, S. Hazra, M. F. C. Guedes da Silva, A. Paula, A. J. L. Pombeiro, CrystEngComm. 2016, 18, 1337-1349.

[4] J. Long, Y. Guari, R. A. S. Ferreira, L. D. Carlos, J. Larionova, Coord. Chem. Rev. 2018, 363, 57-70.

[5] a) G. Cucinotta, M. Perfetti, J. Luzon, M. Etienne, P.-E. Car, A. Caneschi, G. Calvez, K. Bernot, R. Sessoli, Angew. Chem. Int. Ed. 2012, 51, 1606-1610; Angew. Chem. 2012, 124, 1638-1642; b) J. Long, R. Vallat, R. A. S. Ferreira, L. D. Carlos, F. A. A. Paz, Y. Guari, J. Larionova, Chem. Commun. 2012, 48, 9974-9976; c) M. Gregson, N. F. Chilton, A.-M. Ariciu, F. Tuna, I. F. Crowe, W. Lewis, A. J. Blake, D. Collison, E. J. L. McInnes, R. E. P. Winpenny, S. T. Liddle, Chem. Sci. 2016, 7, 155-165; d) S. Shintoyo, K. Murakami, T. Fujinami, N. Matsumoto, N. Mochida, T. Ishida, Y. Sunatsuki, M. Watanabe, M. Tsuchimoto, J. Mrozinski, C. Coletti, N. Re, Inorg. Chem. 2014, 53, 10359-10369; e) E. L. Gavey, M. A. Hareri, J. Regier, L. D. Carlos, R. A. S. Ferreira, F. S. Razavi, J. M. Rawsond, M. Pilkington, J. Mater. Chem. C. 2015, 3, 7738-7747; f) M. A. Hareri, E. L. Gavey, J. Regier, Z. Ras Ali, L. D. Carlos, R. A. S. Ferreira, M. Pilkington, Chem. Commun. 2016, 52, 11335-11338; g) Y.-C. Chen, J.-L. Liu, Y. Lan, Z.-Q. Zhong, A. Mansikkamäki, L. Ungur, Q.-W. Li, J.-H. Jia, L. F. Chibotaru, Chem. Eur. J. 2017, 23, 5708-5715.

[6] a) V. Lorenz, F. T. Edelmann, Adv. Organomet. Chem. 2005, 53, 101-153; b) V. Lorenz, A. Fischer, S. Gießmann, J. W. Gilje, Y. Gun'ko, K. Jacob, F. T. Edelmann, Coord. Chem. Rev. 2000, 206-207, 321-368; c) P. Jutzi, U. Schubert, Silicon Chemistry: From the Atom to Extended Systems, Wiley-VCH, Weinheim, 2007 ; pp. 383-394; d) M. M. Levitsky, A. N. Bilyachenko, Coord. Chem. Rev. 2016, 306, 235-269; e) M. M. Levitsky, Y. V. Zubavichus, A. A. Korlyukov, V. N. Khrustalev, E. S. Shubina, A. N. Bilyachenko, J. Cluster Sci. 2019, 30, $1283-1316$. 
[7] a) W. A. Herrmann, R. Anwander, V. Dufaud, W. Scherer, Angew. Chem. Int. Ed. 1994, 33, 1285-1286; Angew. Chem. 1994, 106, 1338-1340; b) J. Annand, H. C. Aspinall, Dalton Trans. 2000, 1867-1871; c) J. Annand, H. C. Aspinall, A. Steiner, Inorg. Chem. 1999, 38, 3941-3943; d) P. L. Arnold, A. J. Blake, S. N. Hall, B. D. Ward, C. Wilson, Dalton Trans. 2001, 488-491; e) V. Lorenz, S. Gießmann, Y. K. Gun'ko, A. K. Fischer, J. W. Gilje, F. T. Edelmann, Angew. Chem. Int. Ed. 2004, 43, 4603-4606; Angew. Chem. 2004, 116, 4703-4706; f) V. Lorenz, A. Fischer, F. T. Edelmann, J. Organomet. Chem. 2002, 647, 245-249.

[8] a) V. A. Igonin, S. V. Lindeman, Y. T. Struchkov, O. I. Shchegolikhina, Y. A. Molodtsova, Y. A. Pozdnyakova, A. A. Zhdanov, Russ. Chem. Bull. 1993, 42, 168-173; b) V. A. Igonin, S. V. Lindeman, Y. T. Struchkov, Y. A. Molodtsova, Y. A. Pozdnyakova, O. I. Shchegolikhina, A. A. Zhdanov, Russ. Chem. Bull. 1993, 42, 176-181; c) C. Zucchi, O. I. Shchegolikhina, M. Borsari, A. Cornia, G. Gavioli, A. C. Fabretti, E. Rentschler, D. Gatteschi, R. Ugo, R. Psaro, Y. A. Pozdniakova, S. V. Lindeman, A. A. Zhdanov, G. Pályi, J. Mol. Catal. A 1996, 107, 313-321; d) O. I. Shchegolikhina, Y. A. Pozdniakova, S. V. Lindeman, A. A. Zhdanov, R. Psaro, R. Ugo, G. Gavioli, R. Battistuzzi, M. Borsari, T. Rüffer, C. Zucchi, G. Pályi, J. Organomet. Chem. 1996, 514, 29-35.

[9] a) G. Wu, Y. Chen, D.-J. Xu, J.-C. Liu, W. Sun, Z. Shen, J. Organomet. Chem. 2009, 694, 1571-1574; b) V. Lorenz, S. Blaurock, C. G. Hrib, F. T. Edelmann, Eur. J. Inorg. Chem. 2010, 2605-2608; c) G.-L. Davies, J. O'Brien, Y. K. Gun'ko, Sci. Rep. 2017, 7, 45862; d) A. R. Willauer, A. M. Dabrowska, R. Scopelliti, M. Mazzanti, Chem. Commun. 2020, 56, 8936-8939.

[10] S. Marchesi, F. Carniato, E. Boccaleri, New J. Chem. 2014, 38, 2480-2485.

[11] A. N. Kulakova, A. N. Bilyachenko, M. M. Levitsky, V. N. Khrustalev, E. S. Shubina, G. Felix, E. Mamontova, J. Long, Y. Guari, J. Larionova, Chem. A Eur. J. 2020, 26, 16594-16598.

[12] M. Hirotsu, S. Taruno, T. Yoshimura, K. Ueno, M. Unno, H. Matsumoto, Chem. Lett. 2005, 34, $1542-1543$.

[13] A. I. Yalymov, A. N. Bilyachenko, M. M. Levitsky, A. A. Korlyukov, V. N. Khrustalev, L. S. Shul'pina, P. V. Dorovatovskii, M. A. Es'kova, F. Lamaty, X. Bantreil, B. Villemejeanne, J. Martinez, E. S. Shubina, Y. N. Kozlov, G. B. Shul'pin, Catalysts 2017, 7, 101-119.

[14] a) Y.-N. Liu, H.-F. Su, Y.-W. Li, Q.-Y. Liu, Z. Jagličić, W.-G. Wang, C.-H. Tung, D. Sun, Inorg. Chem. 2019, 58, 4574-4582; b) Y.-N. Liu, J.-L. Hou, Z. Wang, R. K. Gupta, Z. Jagličić, M. Jagodič, W.-G. Wang, C.H. Tung, D. Sun, Inorg. Chem. 2020, 59, 5683-5693.

[15] K. Sheng, Y.-N. Liu, R. K. Gupta, M. Kurmoo, D. Sun, Sci. China Chem. 2021, 64, 419-425.

[16] J. Long, F. Habib, P.-H. Lin, I. Korobkov, G. Enright, L. Ungur, W. Wernsdorfer, L. F. Chibotaru, M. Murugesu, J. Am. Chem. Soc. 2011, 133, 5319-5328.

[17] C. Y. Chow, H. Bolvin, V. E. Campbell, R. Guillot, J. W. Kamp, W. Wernsdorfer, F. Gendron, J. Autschbach, V. L. Pecoraro, T. Mallah, Chem. Sci. 2015, 6, 4148-4159.

[18] N. F. Chilton, R. P. Anderson, L. D. Turner, A. Soncini, K. S. Murray, J. Comput. Chem. 2013, 34, 11641175 .

[19] D. N. Woodruff, R. E. P. Winpenny, R. A. Layfield, Chem. Rev. 2013, 113, 5110-5148. 
[20] a) J. Long, E. Mamontova, V. Freitas, D. Luneau, V. Vieru, L. F. Chibotaru, R. A. S. Ferreira, G. Félix, Y. Guari, L. D. Carlos, J. Larionova, RSC Adv. 2016, 6, 108810-108818; b) J. M. Zadrozny, M. Atanasov, A. M. Bryan, C.-Y. Lin, B. D. Rekken, P. P. Power, F. Neese, J. R. Long, Chem. Sci. 2013, 4, 125-138; c) Stephen T. Liddle, Joris van Slageren Chem. Soc. Rev. 2015, 44, 6655-6669.

[21] a) I. E. Kolesnikov, D. V. Mamonova, E. Lähderanta, A. V. Kurochkin, M. D. Mikhailov, J. Lumin. 2017, 187, 26-32; b) J. Kuang, Y. Liu, J. Zhang, J. Solid State Chem. 2006, 179, 266-269; c) P. Babu, K. H. Jang, E. S. Kim, L. Shi, H. J. Seo, F. Rivera-López, U. R. Rodríguez-Mendoza, V. Lavín, R. Vijaya, C. K. Jayasankar, L. Rama Moorthy, J. Appl. Phys. 2009, 105, 13516.

[22] I. E. Kolesnikov, A. A. Kalinichev, M. A. Kurochkin, E. V. Golyeva, A. S. Terentyeva, E. Yu. Kolesnikov, E. Lähderanta, Sci. Rep. 2019, 9, 2043.

[23] J. Long, J. Rouquette, J.-M. Thibaud, R. A. S. Ferreira, L. D. Carlos, B. Donnadieu, V. Vieru, L. F. Chibotaru, L. Konczewicz, J. Haines, Y. Guari, J. Larionova, Angew. Chem. Int. Ed. 2015, 54, 2236-2240; Angew. Chem. 2015, 127, 2264-2268.

[24] I. G. N. Silva, J. Kai, M. C. F. C. Felinto, H. F. Brito, Opt. Mater. 2013, 35, 978-982. 